\title{
Evaluation of Mechanical and Water Absorption Properties of Alkaline-Treated Sawdust-Reinforced Polypropylene Composite
}

\author{
Eyasu Ferede $\mathbb{D}$ \\ Ethiopian Institute of Textile and Fashion Technology, Bahir Dar University, Bahir Dar, Ethiopia \\ Correspondence should be addressed to Eyasu Ferede; eyasuferede1982@gmail.com
}

Received 24 August 2020; Revised 31 October 2020; Accepted 8 December 2020; Published 16 December 2020

Academic Editor: Yuanxin Zhou

Copyright (c) 2020 Eyasu Ferede. This is an open access article distributed under the Creative Commons Attribution License, which permits unrestricted use, distribution, and reproduction in any medium, provided the original work is properly cited.

\begin{abstract}
Sawdust is a natural composite obtained from natural resources such as shrubs and trees and in a large amount from the wood industry as a waste. This study aimed to evaluate the mechanical and water absorption properties of alkaline-treated wood sawdust-reinforced polypropylene composite. The composites were manufactured by the melt-mixing method followed by compression molding with amounts of wood sawdust ranging from 10, 20, 30, and 40 to 50 wt. \% by volume. The produced composites were characterized for their mechanical and water absorption characteristics. The results indicated that increasing the amount of wood sawdust content up to $40 \%$ improves the tensile, flexural, impact, and compressive strength of the composites but after the wood sawdust contents reach $40 \%$, the mechanical properties of the composite were decreased. Water absorption rate has increased with an increase in the wood sawdust proportion; this is due to the presence of -OH groups on the surface of wood particles. From the result of this study, it can be also concluded that the optimal mechanical and water absorption properties were attained at $40 \%$ wood sawdust content. Therefore, sawdust can be used as filler and reinforcement in the PP matrix, which will reduce cost and give environmental benefits.
\end{abstract}

\section{Introduction}

Over the past two decades, with increasing deforestation for wood around the world, most research and researchers are frequently trying to come up with new ideas to develop a wood-based alternative to achieve the demand on this natural resource and save the future happiness of the nature earth. In terms of innovation and quality of materials, technology has formed new products derivative from wood, either in different forms or in combination with other materials, or by making wood-plastic composites (WPC) made up of wood waste and plastic material in the exploration of environmental welfares, and with better product performance [1-3]. Wood sawdust is substance significantly used in reinforcing polymer from both a technical and a marketable point of view $[4,5]$. Polymer composites are recommended for use in outdoor applications and marine infrastructures but composites have found numerous applications in aerospace, automotive, and construction industries owing to their lightweight, high specific strength, high specific stiffness, and other performance benefits [6,7]. Composites are collection materials mainly containing wood and thermoplastic polymers for this study were used PP as a thermoplastic matrix due to various vital and suitable features such as clearness, dimensional inflexibility, ease of processing, low cost, high recyclability, antiflame properties, high heat distortion temperature, and high impact strength. The reinforcement was used for this study wood in the form of sawdust [8-12].

Wood sawdust is a natural compound found in natural resources such as shrubs and trees and in a big quantity from wood manufacturing as a waste. Wood is lignocellulose, hygroscopic, cellular, and anisotropic material. It is made up of main components (cellulose, hemicellulose, and lignin) and slight components (ash and extractives). The main components are structural constituents with a high molecular weight. Wood is approximately $60-75 \%$ cellulose, $20-30 \%$ lignin, $1-10 \%$ extractives, and $0.45 \%$ ash. The chemical composition of wood varies between species [13-15]. Currently, numerous producers of WPC around the 
world focus on biodegradable material, particularly the manufacturing industry developing with natural resources in order to provide the continuance of a healthy atmosphere. One of the natural resources is wood waste. To evade ecological contamination and expenditure of the resources, wood waste is collected to make a natural composite in its place of synthetic fibers $[16,17]$.

In recent years, natural fibers and dust have been extensively used as reinforcing fillers on behalf of mineral fillers and synthetic fibers in the thermoplastic polymer matrix. Reinforced polymeric composites were made using cellulose and lignocellulosic materials. These natural fillers have several advantages, such as their renewability, biodegradability, recyclability, low density, low cost, good thermal and acoustic insulation, and acceptable specific mechanical properties [18-20]. Despite the advantages of natural fibers, they exhibit some drawbacks, such as large variability, lower mechanical properties, lower impact resistance, and poor moisture resistance compared with synthetic fibers [20]. However, the major drawbacks of natural fiber-reinforced composites (NFRPCs) are the incompatibility between the hydrophilic natural fiber and hydrophobic polymer leading to the formation of narrow and weak interphase. This could also lead to the nonuniform dispersion of fiber with the matrix. To overcome this drawback, particle or fiber surface treatment can be applied. Alkaline treatment or mercerization is one of the most used chemical treatments of natural fibers when used to reinforce thermoplastics and thermosets. After alkali treatment, parts of the reinforcing materials such as hemicellulose and lignin were removed, increasing surface roughness resulting in better mechanical interlocking and increasing the amount of cellulose exposed on the fiber surface, thus increasing the number of possible reaction sites. Besides, delignification works as fibrillation, leaving many cavities and interspaces between cellulose microfibrils $[19,21-24]$.

Agricultural residues such as bagasse, rice husks, and wood chips are mainly important natural resources. These natural fillers are lighter and cheaper and provide much higher strength [18]. Among these agricultural residues, wood waste is the most usually used lignocellulosic reinforcement due to its ease of handling, low pretreatment cost, and widespread availability [25]. These residues of the furniture industry, such as wood or sawdust, can be used in polymer-fiber composites as a filler or reinforcement with several benefits and it also satisfies the greening requirements such as being nonabrasive during processing, low in cost, widely available, eco-friendly renewable filler, and sustainable, biodegradation, high filling levels possible, high specific properties, lower density per weight of raw material, flexibility, and recyclability as well as desirable mechanical properties $[2,3,26-32]$.

There are few studies related to the mechanical properties of WPC from polymer and wood sawdust. Islam and Islam studied the characterization of chemically modified sawdust-reinforced recycled polyethene composites. They found that the mechanical properties of the chemically treated sawdust-reinforced composites were found to be improved compared to those of the untreated ones [19].
Rahman et al. studied the mechanical properties of sawdustreinforced recycled polyethylene terephthalate (PET) composite. They found that the optimum sawdust content at $40 \%$ of the modulus of elasticity (MOE) and modulus of rupture is improved [33]. Medupin et al. studied the mechanical properties of wood waste reinforced low-density polyethylene matrix composites. They found that $40 \%$ of wood waste was the optimum reinforcement [34]. Ashori studied the mechanical properties of wood fibre/polypropylene composite. The results clearly showed that the fiber loading of 30 and $40 \mathrm{wt}$. \% of the tensile and flexural strength of the composite is increased [35]. Abd El-bak studied evaluation of mechanical properties of jute/glass/carbon fiber reinforced hybrid composites. The results from this study clearly showed that the hybridization process can potentially improve the tensile and flexural properties of jute reinforced composite [36].

Very little work has been done on the incorporation of wood sawdust as a filler and reinforcing raw material in thermoplastic composite manufacturing. However, to the author's knowledge, there is no study on the utilization of alkaline-treated wood sawdust as filler and reinforcing material in PP matrix composite production. The present study focused on the manufacturing of composites from sawdust and PP. However, the main aim of this research was to study the effect of wood sawdust content on the tensile strength, flexural strength, impact resistance, compressive strength, and water absorption properties of the PP matrix. The wood sawdust can be used as filler and reinforcement in the PP matrix, which will reduce cost and give environmental benefits.

\section{Materials and Methods}

\subsection{Materials}

2.1.1. Reinforcement. Sawdust was obtained from the local sawmill in Gondar, Ethiopia. The properties of wood sawdust used for this study are given in Table 1.

2.1.2. Polymer Matrix. Polypropylene (Marlex ${ }^{\circledR}$ HGX030SP) was supplied by Saudi Polymers Company, Jubail, Saudi Arabia. The physical and mechanical properties of the PP used for this study are given in Table 2 .

2.1.3. Chemicals. Sodium hydroxide $(\mathrm{NaOH})$ and acetic acid $\left(\mathrm{CH}_{3} \mathrm{COOH}\right)$ in pellets form was procured from the local suppliers in Addis Ababa, Ethiopia.

\subsection{Method}

2.2.1. Preparation of Sawdust Samples. The sawdust samples were sun-dried for two days to remove excess moisture. After that, the wood sawdust was sieved out by using 1-2 mm sieve (Figure 1) which helps to remove some unwanted materials such as pieces of plastic, pieces of metals, and wood particles. Wood sawdust serves as filler and reinforcement in the matrix. 
Table 1: Properties of wood sawdust.

\begin{tabular}{lc}
\hline Properties & Sawdust \\
\hline Particle size & $1-2 \mathrm{~mm}$ \\
Bulk density & $0.124 \mathrm{~g} / \mathrm{cm}^{3}$ \\
\hline
\end{tabular}

TABle 2: Properties of polypropylene.

\begin{tabular}{lc}
\hline Properties & $\mathrm{PP}$ \\
\hline Density & $0.906 \mathrm{~g} / \mathrm{cm}^{3}$ \\
Heat deflection temperature, $0.46 \mathrm{MPa}$ & $101^{\circ} \mathrm{C}$ \\
Melting point & $170^{\circ} \mathrm{C}$ \\
Melt flow rate, $230^{\circ} \mathrm{C} / 2.16 \mathrm{~kg}$ & $3 \mathrm{~g} / 10 \mathrm{~min}$ \\
Tensile strength at yield, $50.8 \mathrm{~mm} / \mathrm{min}$ & $37 \mathrm{MPa}$ \\
Flexural modulus, secant, $1.3 \mathrm{~mm} / \mathrm{min}$ & $1,590 \mathrm{MPa}$ \\
Notched izod impact, $23^{\circ} \mathrm{C}$ & $31 \mathrm{~J} / \mathrm{m}$ \\
\hline
\end{tabular}

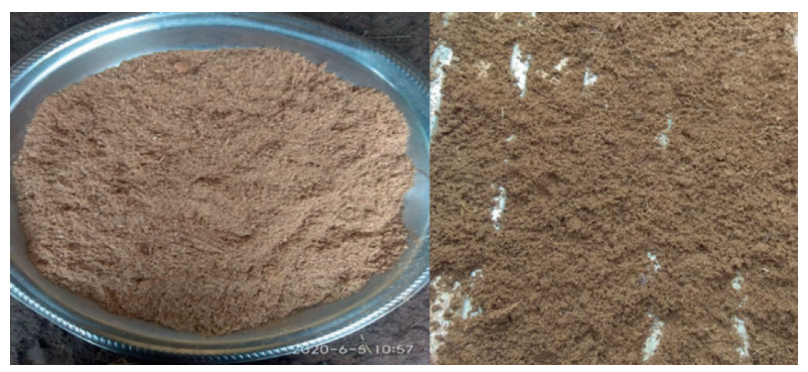

FIGURE 1: Sieved wood sawdust.

2.2.2. Chemical Treatment of Wood Sawdust. To know the effect of chemical treatment of wood particles on the composite properties, the dried, cleaned, and sieved wood sawdust was soaked in $\mathrm{NaOH}$ solution with $5 \%$ concentration at room temperature for 2 hours. After that the reinforcement was washed several times with distilled water to remove any $\mathrm{NaOH}$ solution sticking to the reinforcement surface, neutralized with acetic acid, and again washed with distilled water. Finally, wood sawdust reinforcement was dried in sunlight for 3 days before continuing manufacturing the composites [37].

\subsubsection{Preparation of Sawdust-Reinforced PP Composite.} The PP-wood sawdust composites were prepared by the meltmixing method followed by compression molding. Initially the sawdust was added to a melt of polypropylene and mixing was carried out at a temperature of $170^{\circ} \mathrm{C}$ and a rotor speed of $50 \mathrm{rpm}$ for a duration of $10 \mathrm{~min}$ as reported elsewhere [38]. Composites sized $200 \times 50 \times 20 \mathrm{~mm}^{3}$ were prepared using an open mold. The mold was refined with a release agent to avoid PP stabbing to it. The process involved melting of the $\mathrm{PP}$, adding a prearranged proportion of the sieved sawdust, melt-mixing thoroughly to form a homogeneous viscous solution, and placing it into the prepared mold. Finally, the mold was closed, and the samples were cooled down to room temperature under $12 \mathrm{MPa}$ pressure for 30 minutes. Finally, the samples were removed from the mold after the curing process. The specimens of the composites produced were shaped by sandpaper and used for testing as shown in Figure 2.

\subsubsection{Characterization of Composite Samples}

(1) Tensile Strength Test. Tensile strength refers to the amount of stress a material can handle before it breaks, cracks, becomes deformed, or otherwise fails. The tensile properties of the composite specimens were measured with a Deepak universal testing machine (DTRX) according to ASTM D 638-14 [39]. The dimensions of the test specimens were $10 \times 5 \times 20 \mathrm{~mm}^{3}$. Five specimens of each composite were tested, and an average value was reported.

(2) Flexural Strength Test. Flexural strength is a material or structure's ability to withstand bending. The flexural properties of the composite specimens were measured with a Deepak Universal Testing Machine (DTRX) according to ASTM D790-00 [40]. The dimensions of the test specimens were $10 \times 5 \times 20 \mathrm{~mm}^{3}$. Five specimens of each composite were tested, and an average value was reported.

(3) Impact Strength Test. Charpy impact tests also known as the Charpy V-notch test on unnotched specimens were performed using impact testing machine JBS-500B model. The test specimens were prepared according to the ASTM D4812-19 [41] test standard with sample dimension of $40 \times 50 \times 20 \mathrm{~mm}^{3}$. Five specimens of each composite were tested, and an average value was reported.

(4) Compressive Strength Test. Compressive strength indicates the force applied to the top and bottom of a test sample until the sample fractures or is deformed or the resistance of a material breaks under compression. The compressive properties of the composite specimens were measured with a Deepak universal testing machine (DTRX) according to ASTM D6641/D6641M-16e1 [42] test standard with sample dimension of $40 \times 50 \times 20 \mathrm{~mm}^{3}$. Five specimens of each composite were tested, and an average value was reported.

(5) Water Absorption Test. Water absorption tests were carried out as per ASTM D570-98 [43] test method. Samples of each composite type were oven-dried before its weight was recorded as the initial weight of the composites. The samples were then placed in distilled water and maintained at room temperature $\left(25^{\circ} \mathrm{C}\right)$ for 24 hours. The samples were then removed from the water, dried, and weighed. The amount of water absorbed by the composites (in percentage) was calculated using the following equation:

$$
\% W=\frac{(W t-W o)}{W o} \times 100,
$$

where $W t$ is the weight of composite after water immersion and $W o$ is the weight of a dried sample.

\section{Results and Discussion}

3.1. Effect of Sawdust Content on Tensile Strength. The properties of tensile strength wood sawdust-PP composites at different wood sawdust content are shown in Figure 3. The result showed that the tensile strength increases with the increase in sawdust content up to $40 \% \mathrm{Wt}$. This is due to 


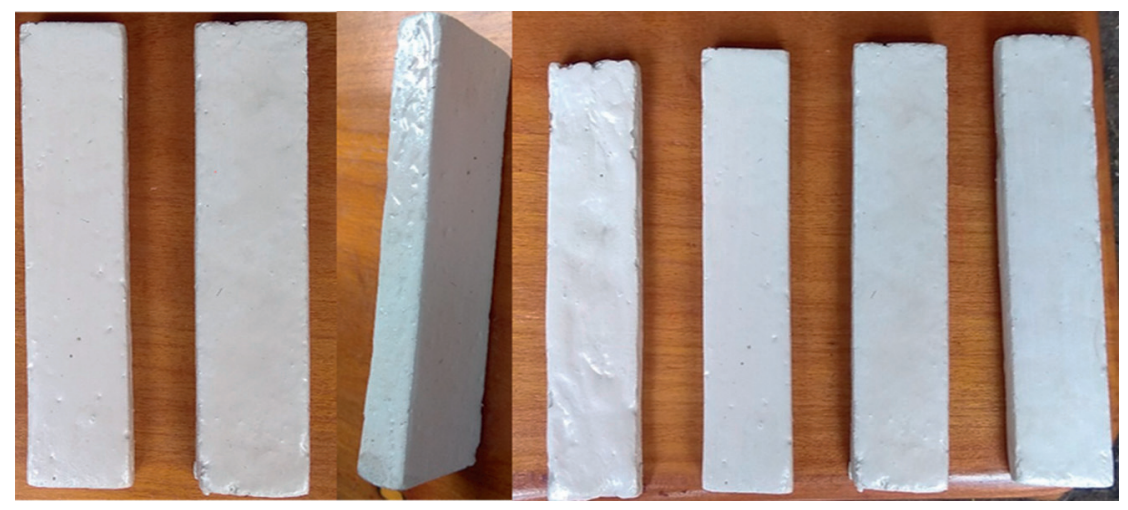

FIgURE 2: Wood sawdust-reinforced polypropylene composites.

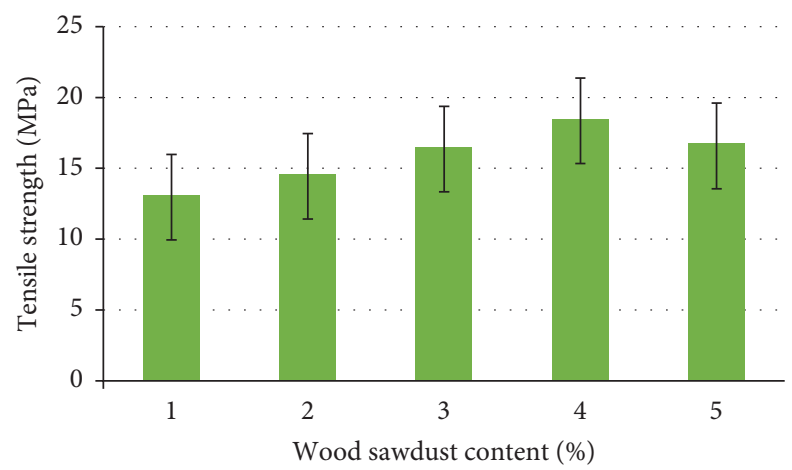

Figure 3: Effect of sawdust content on tensile strength.

strong interfacial bonding between the sawdust and the pp matrix. The increment in tensile strength, as a result of wood sawdust incorporation, can be attributed to the intrinsic adhesion of the wood sawdust-matrix interface. This adhesion enables good stress transfer from the polymer matrix to wood particles during stressing, causing an increase in tensile strength up to the optimum levels [44]. The increase in tensile strength with an increase in the wood sawdust weight fraction reveals that the incorporation of the wood sawdust into the matrix provides effective reinforcement [45]. From this result, it can be observed that the optimum tensile strength was achieved at $40 \%$ wood sawdust content and $60 \%$ PP matrix content. This is probably due to more stress transfer from the matrix to sawdust.

However, the tensile strength of the produced composite starts decreasing with further addition of wood sawdust content above $40 \%$ (Figure 3). This decrement might be due to the poor interfacial interaction between the sawdust and PP. This could happen due to the availability of more sawdust particles per unit cross-section area of the composite and hence the fracture stress (breaking strength) increases. The reduction in tensile strength as the wood sawdust content increased; this can also be attributed to the weak interfacial bonding between filler (hydrophilic) and the matrix polymer (hydrophobic), which decreased the tensile strength of the composite because of the inability of the reinforcement to support the stress transferred from the polymer matrix. In general, this weak interfacial adhesion allowed the formation of micro crack and fiber agglomerates due to preferential fibre-fibre interaction as well as no uniform stress transfer from the fiber to the matrix [17-19].

The decrease in tensile strength with an increase in the sawdust content is probably due to either the aggregation of the sawdust or insufficient hydrogen bonding between the pp matrix and the sawdust. Usually, the orientation of the sawdust in the composites influences the tensile strength of the fiber-reinforced composite [45]. This happens because as the sawdust content increases, weak interfacial area between the sawdust and the matrix by hydroxyl group in the sawdust increases. On the other hand, the increase of filler content also produced more filler end. This means that there are considerable stress concentration points taking place by agglomeration of the filler particles and dewetting of the polymer at interphase aggravates the situation by creating stress concentration points, and the poor interfacial bonding causes partially separated micro spaces between sawdust and polymer matrix [21]. As reported by Ashori and Nourbakhsh also various parameters influence the tensile properties of wood saw dust-reinforced composites including the fiber aspect ratio, fiber-matrix adhesion, stress transfer at the interface, and mixing temperatures [46]. As it is clearly seen in Figure 3, the maximum tensile strength of composite produced from saw dust was $18.36 \mathrm{MPa}$. The result attained in this study is in agreement with the previous researches 
and literatures that show that the tensile strength of PP/Rice husk filler was $22 \mathrm{MPa}$ [47], PP/coir fiber was $37.90 \mathrm{MPa}$ [48], and PP/sisal fiber composite was $28 \mathrm{MPa}$ [49].

3.2. Effect of Sawdust Content on Flexural Strength. The effects of sawdust content on the flexural strength of the composites are shown in Figure 4. The result shows that the flexural strength of the composites increases with the increase in sawdust content up to $40 \% \mathrm{Wt}$. as reported by Islam and Islam. This may be due to the effect of satisfactory mechanical interlocking or entanglement of the polymer chain matrix with the sawdust which results in effective stress transfer from the matrix to the reinforcement [19]. From the observation, the highest or optimum flexural strength was achieved at $40 \%$ wood sawdust contents. This is due to the good bond achieved between the mixture PP and wood sawdust [10]. This may be also due to the orientation of this wood sawdust [18]. As reported by Idrus et al., when the sawdust loading increases, the flexural strength gradually increases and this could be also due to the increase in resistance to shearing in the composites structure probably because of the presence of the sawdust [15]. This suggests that this material may have better dispersion of sawdust in the composite as [50]. The addition of sawdust has significantly increased the flexural strength of the composites due to its high modulus; higher fiber concentration demands higher stress for the same deformation and increased reinforcement-matrix adhesion provides increased stress transfer from the matrix to the reinforcement [22].

However, as shown in Figure 4, the flexural strength of the composite decreases above $40 \%$ of the wood sawdust content. This decrease is attributed to the inability of the reinforcement to support stresses transferred from the polymer matrix, and poor interfacial bonding generates partially spaces between reinforcement and matrix materials which generates a weak structure [51]. It is also not possible to achieve a high value of flexural strength with a high amount of wood dust above $40 \%$ because the higher amount of wood dust may form the cluster at various locations in the composite which form a weak bonding. This could allow for crack formation in composite material during the flexural test which results in reduced flexural load-bearing capability of the composites $[52,53]$. The result data in Figure 4 show that the maximum attained flexural strength of the composite was $46.1 \mathrm{MPa}$. This result is in accordance with the flexural strength of lignocellulosic fillers (pine wood sawdust/walnut shell flour/black rice husk powder) reinforced polypropylene composite [54] and $\mathrm{PP} /$ sisal fiber composite [49] with 43.4 MPa and around 42 MPa flexural strength, respectively.

3.3. Effect of Sawdust Content on Impact Strength. The impact strength (IS) of a material can be defined by its capacity to absorb and dissipate energies under impact or shock loading and is a measure of the toughness of the composite. The effect of wood sawdust content on the impact strength of the composite is shown in Figure 5. The impact strength of the composites increases with increasing wood sawdust content up to $40 \% W t$ (Figure 5). The increment in impact strength could be due to strong interfacial bonding between the matrix and the sawdust; this strong bonding requires more energy to break the wood sawdust during the fracture [55].

However, there is a gradual decrease in IS values with an increase in sawdust content above $40 \%$. It has been reported that when a crack is generated due to impact, it propagates toward a poor interfacial bonding. With an increase in sawdust content, the impact strength of the produced composite tends to decrease because of an increase in the regions of poor interfacial wetting. Poor interfacial bonding results in micro spaces at the fiber-matrix interface and these causes numerous micro cracks, which induce crack propagation through the composite. It was evident that higher wood sawdust loading increases the probability of fiber agglomeration, and its stress concentration requires less energy to initiate and propagate cracks. Generally, the toughness of fiber-reinforced polymer composite is dependent on the fiber, the polymer matrix, and the interfacial bond strength $[19,56]$. The degree of adhesion, fiber pullout, and a mechanism to absorb energy are some of the parameters that can influence the impact strength of cellulosic fibers/plastics composites [35].

3.4. Effect of Sawdust Content on Compressive Strength. Compressive strength refers to the ability of a certain composite material or structural element to withstand loads that reduce the size of that composite material, or structural element when applied. A force is applied to the top and bottom of a test sample, until the sample fractures or is deformed. The effect of sawdust content on the compressive strength of wood sawdust-reinforced PP composite is shown in Figure 6. The result in Figure 6 shows that the compressive strength of the produced composites increases with the increase in the wood sawdust contents up to $40 \% \mathrm{Wt}$. This is due to the reinforcement imparted by the wood sawdust which allows stress transfer from the matrix to the sawdust, higher wood sawdust PP matrix compatibility, composites being more compact or dense, and good interfacial bonding between wood sawdust and matrix [57]. From the observation, the optimum compressive strength of the composite reached $40 \% W t$. of wood sawdust content. The increase in the compressive strength may be attributed to the increase of bonding force between the pp matrix and wood sawdust.

However, as it is clearly seen in Figure 6, the increment of the percentage of sawdust content beyond $40 \%$ results in decline of the compressive strength of the produced composite. This decrease may be due to weak interfacial bonding between sawdust and matrix material. Another possible explanation could be the presence of higher sawdust particle in the produced composite that will be highly vulnerable to the formation of cracks due to low dispersion of sawdust in the matrix [58].

3.5. Effect of Sawdust Content on Water Absorption. The water absorption characteristics of the produced composites with various loading ratio are shown in Figure 7. As it is clearly seen in Figure 7, the water absorption of composites 


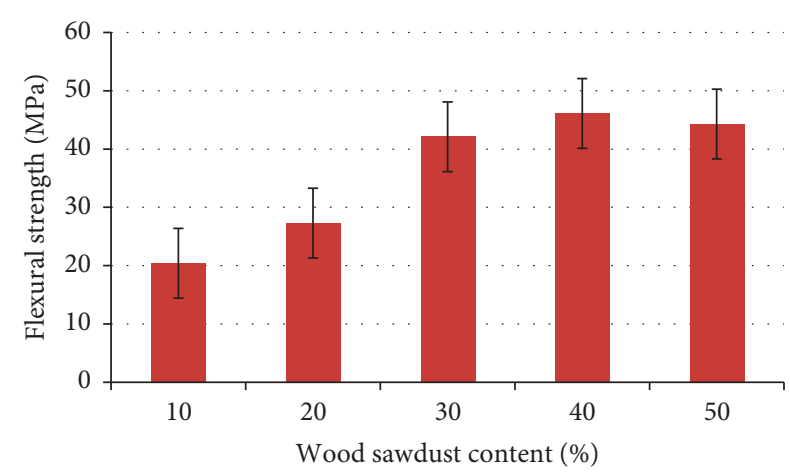

Figure 4: Effect of sawdust content on flexural strength.



Figure 5: Effect of sawdust content on impact strength.

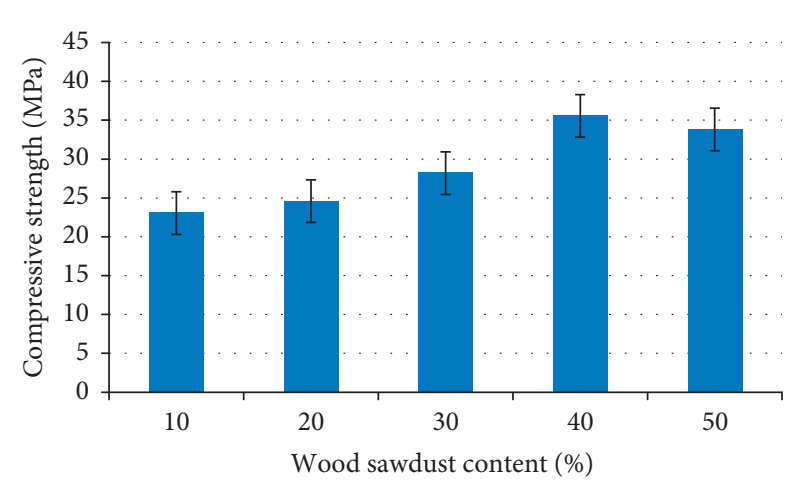

FIGURE 6: Effect of sawdust content on compressive strength.

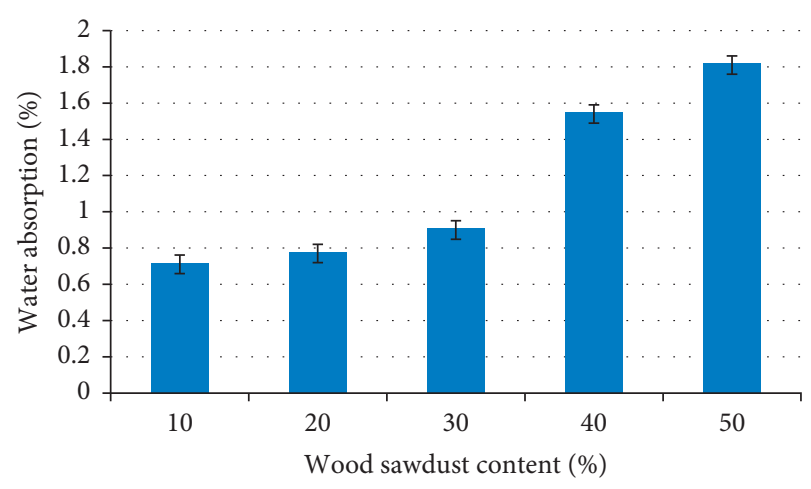

FIgURE 7: Effect of sawdust content on water absorption. increases with the increase in sawdust content. This will be due to the formation of less surface interaction between the matrix and sawdust when mixed giving higher water absorption [59]. This is due to the presence of higher contents of filler and reinforcement loading in the composites that can absorb more water. When the content of the wood sawdust increases in the composite, the presence of free $-\mathrm{OH}$ groups in the cellulose and hemicellulose structure increases and then these hydrophilic wood particles absorb water through hydrogen bonding between water molecules and the $\mathrm{OH}$-groups on the surface of wood particles $[15,56,60,61]$.

\section{Conclusions}

The purpose of the present study was to evaluate the mechanical and water absorption properties of alkaline-treated wood sawdust-reinforced polypropylene composite. From the above investigations, the following conclusions can be drawn:

(i) The results indicated an increase in tensile, flexural, impact, and compressive strength of composites with the addition of wood sawdust content up to $40 \%$. Further addition of the reinforcement above $40 \%$ resulted in a decrement of the mechanical properties.

(ii) The maximum tensile, flexural, compressive, and impact strength were obtained at $40 \%$ of wood sawdust contents with $18.36 \mathrm{MPa}, 46.1 \mathrm{MPa}$, $35.56 \mathrm{MPa}$, and $17.14 \mathrm{~J} / \mathrm{cm}^{2}$ values, respectively.

(iii) The water absorption results indicate that the sawdust content increases from $10 \%$ up to $50 \%$ and the water absorption properties of the composite increase; this is due to the hydrophilic character of wood sawdust but the lowest and the highest water absorption rate were obtained with $10 \%$ and 50\% reinforcement, respectively.

(iv) From observation, the optimum mechanical and water absorption properties were achieved at $40 \%$ of wood sawdust content.

(v) The result of the present study reveals that wood sawdust pp composite with good mechanical properties could be successfully developed using the appropriate wood sawdust composition. The wood sawdust can be used as filler and reinforcement in the PP matrix, which will reduce cost and give environmental benefits.

(vi) The future study will entail on mechanical characterization and SEM analysis of the optimized composite.

\section{Data Availability}

All data are included within the manuscript.

\section{Conflicts of Interest}

The author declares that there are no conflicts of interest regarding the publication of this paper. 


\section{Acknowledgments}

The author would like to thank Ethiopian Institute of Textile and Fashion Technology, Bahir Dar University, Bahir Dar, Ethiopia, for providing funding and laboratory facilities.

\section{References}

[1] K. S. Chun, V. Subramaniam, C. M. Yeng et al., "Wood plastic composites made from post-used polystyrene foam and agricultural waste," Journal of Thermoplastic Composite Materials, vol. 32, no. 11, pp. 1455-1466, 2019.

[2] Y. M. López, J. B. Paes, E. M. Rodríguez, D. Gustave, and F. G. Gonçalves, "Wood particleboards reinforced with thermoplastics to improve thickness swelling and mechanical properties," Cerne, vol. 24, no. 4, pp. 369-378, 2018.

[3] S. Haq and R. Srivastava, "Wood polypropylene (PP) composites manufactured by mango wood waste with virgin or recycled PP: mechanical, morphology, melt flow index and crystalline behaviour," Journal of Polymers and the Environment, vol. 25, no. 3, pp. 640-648, 2017.

[4] M. F. Hossain, M. K. Islam, and M. A. Islam, "Effect of chemical treatment on the mechanical and physical properties of wood saw dust particles reinforced polymer matrix composites," Procedia Engineering, vol. 90, pp. 39-45, 2014.

[5] H. Jaya, N. Z. Noriman, H. K. AbdulKadir et al., "The effects of wood sawdust loading on tensile and physical properties of up/pf/wsd composites," IOP Conference Series: Materials Science and Engineering, vol. 454, Article ID 012193, 2018.

[6] M. A. Abd El-baky, "Impact performance of hybrid laminated composites with statistical analysis," Iranian Polymer Journal, vol. 27, no. 7, pp. 445-459, 2018.

[7] M. Abd El-baky, "Experimental investigation on impact performance of glass-polypropylene hybrid composites: effect of water aging," Journal of Thermoplastic Composite Materials, vol. 32, no. 5, pp. 657-672, 2019.

[8] C.-S. Javier, A.-R. Sergio, Z.-G. Roberto, and D.-D. Jorge, "Optimization of the tensile and flexural strength of a woodPET composite," Ingeniería, Investigación Y Tecnología, vol. 16, no. 1, pp. 105-112, 2015.

[9] A. T. Azeez, "A review of wood plastic composites effect on the environment," Journal of University of Babylon, vol. 25, no. 2, pp. 360-367, 2017.

[10] S. Subramonian, A. Ali, M. Amran, L. D. Sivakumar, S. Salleh, and A. Rajaizam, "Effect of fiber loading on the mechanical properties of bagasse fiber-reinforced polypropylene composites," Advances in Mechanical Engineering, vol. 8, no. 8, Article ID 1687814016664258, 2016.

[11] L. P. Dos Santos, T. S. Flores-Sahagun, and K. G. Satyanarayana, "Effect of processing parameters on the properties of polypropylene-sawdust composites," Journal of Composite Materials, vol. 49, no. 30, pp. 3727-3740, 2015.

[12] S. K. Najafi, E. Hamidinia, and M. Tajvidi, "Mechanical properties of composites from sawdust and recycled plastics," Journal of Applied Polymer Science, vol. 100, no. 5, pp. 3641-3645, 2006.

[13] K. O. Niska and M. Sain, Wood-polymer Composites, Woodhead Publishing, Cambridge, UK, 2008.

[14] L. M. Matuana and N. M. Stark, "The use of wood fibers as reinforcements in composites," in Biofiber Reinforcements in Composite Materials, pp. 648-688, Woodhead Publishing, Cambridge, UK, 2015.

[15] M. A. M. M. Idrus, S. Hamdan, M. R. Rahman, and M. S. Islam, "Treated tropical wood sawdust-polypropylene polymer composite: mechanical and morphological study," Journal of Biomaterials and Nanobiotechnology, vol. 2, no. 4, p. 435, 2011.

[16] R. Ramkumar and P. Saravanan, "Assessment of composites using waste sugarcane bagasse fiber and wood dust powder," International Journal of Innovative Technology and Exploring Engineering (IJITEE), vol. 9, no. 5, pp. 2126-2131, 2020.

[17] V. Gulitah and K. C. Liew, "Morpho-mechanical properties of wood fiber plastic composite (WFPC) based on three different recycled plastic codes," International Journal of Biobased Plastics, vol. 1, no. 1, pp. 22-30, 2019.

[18] B. Ramaraj, "Mechanical and thermal properties of polypropylene/sugarcane bagasse composites," Journal of Applied Polymer Science, vol. 103, no. 6, pp. 3827-3832, 2007.

[19] M. N. Islam and M. S. Islam, "Characterization of chemically modified sawdust-reinforced recycled polyethylene composites," Journal of Thermoplastic Composite Materials, vol. 28, no. 8, pp. 1135-1153, 2015.

[20] M. A. Abd El-Baky, M. A. Attia, M. M. Abdelhaleem, and M. A. Hassan, "Flax/basalt/E-glass fibers reinforced epoxy composites with enhanced mechanical properties," Journal of Natural Fibers, vol. 18, pp. 1-15, 2020.

[21] M. H. Alzuhairi, K. M. Shabbeb, and S. A. H. Alsaedy, "Heat and chemical treatments for sawdust/UPE composites," Engineering and Technology Journal, vol. 34, no. 8, pp. 16241635, 2016.

[22] M. R. Rahman, M. N. Islam, and M. M. Huque, "Influence of fiber treatment on the mechanical and morphological properties of sawdust reinforced polypropylene composites," Journal of Polymers and the Environment, vol. 18, no. 3, pp. 443-450, 2010.

[23] X. Li, L. G. Tabil, and S. Panigrahi, "Chemical treatments of natural fiber for use in natural fiber-reinforced composites: a review," Journal of Polymers and the Environment, vol. 15, no. 1, pp. 25-33, 2007.

[24] X. Jiang, J. Wang, G. Wu, X. Peng, and X. Ma, "Significant reinforcement of polypropylene/wood flour composites by high extent of interfacial interaction," Journal of Thermoplastic Composite Materials, vol. 32, no. 5, pp. 577-592, 2019.

[25] M. C. N. Yemele, A. Koubaa, A. Cloutier, P. Soulounganga, and M. Wolcott, "Effect of bark fiber content and size on the mechanical properties of bark/HDPE composites," Composites Part A: Applied Science and Manufacturing, vol. 41, no. 1, pp. 131-137, 2010.

[26] T. Akbulut, M. Akkuş, and N. Ayrilmiş, "Mechanical properties of wood polypropylene composites produced by using resin impregnated paper waste," Machines. Technologies Materials, vol. 10, no. 5, pp. 38-40, 2016.

[27] D. Basalp, F. Tihminlioglu, S. C. Sofuoglu, F. Inal, and A. Sofuoglu, "Utilization of municipal plastic and wood waste in industrial manufacturing of wood plastic composites," Waste and Biomass Valorization, vol. 11, pp. 5419-5430, 2020.

[28] V. N. Hristov, R. Lach, and W. Grellmann, "Impact fracture behavior of modified polypropylene/wood fiber composites," Polymer Testing, vol. 23, no. 5, pp. 581-589, 2004.

[29] Z.-X. Zhang, C. Gao, Z. X. Xin, and J. K. Kim, "Effects of extruder parameters and silica on physico-mechanical and foaming properties of PP/wood-fiber composites," Composites Part B: Engineering, vol. 43, no. 4, pp. 2047-2057, 2012.

[30] S. Kumar, A. Vedrtnam, and S. J. Pawar, "Effect of wood dust type on mechanical properties, wear behavior, biodegradability, and resistance to natural weathering of wood-plastic composites," Frontiers of Structural and Civil Engineering, vol. 13, no. 6, pp. 1446-1462, 2019. 
[31] É. Hillig, E. Freire, A. J. Zattera, G. Zanoto, K. Grison, and M. Zeni, "Use of sawdust in polyethylene composites," Progress in Rubber, Plastics and Recycling Technology, vol. 24, no. 2, pp. 113-119, 2008.

[32] M. A. Abd El-Baky, M. Megahed, H. H. El-Saqqa, and A. E. Alshorbagy, "Mechanical properties evaluation of sugarcane bagasse-glass/polyester composites," Journal of Natural Fibers, vol. 18, pp. 1-18, 2019.

[33] K. S. Rahman, M. N. Islam, M. M. Rahman, M. O. Hannan, R. Dungani, and H. A. Khalil, "Flat-pressed wood plastic composites from sawdust and recycled polyethylene terephthalate (PET): physical and mechanical properties," Springer Plus, vol. 2, no. 1, p. 629, 2013.

[34] R. Medupin, O. K. Abubakre, K. O. Ukoba, and P. E. Imoisili, "Mechanical properties of wood waste reinforced polymer matrix composites," American Chemical Science Journal, vol. 3, no. 4, pp. 507-513, 2013.

[35] A. Ashori, "Study on mechanical properties of wood fiber/ polypropylene composites," in Advanced Materials Researchvol. 123, pp. 1195-1198, Trans Tech Publications Ltd, 2010.

[36] M. A. Abd El-baky, "Evaluation of mechanical properties of jute/glass/carbon fibers reinforced hybrid composites," Fibers and Polymers, vol. 18, no. 12, pp. 2417-2432, 2017.

[37] H. Jaya, M. F. Omar, H. Md Akil, Z. A. Ahmad, and N. N. Zulkepli, "Effect of alkaline treatment on sawdust reinforced high density polyethylene composite under wide strain rate," in Materials Science Forumvol. 840, pp. 103-107, Trans Tech Publications Ltd, 2015.

[38] P. V. Joseph, K. Joseph, and S. Thomas, "Short sisal fiber reinforced polypropylene composites: the role of interface modification on ultimate properties," Composite Interfaces, vol. 9, no. 2, pp. 171-205, 2002.

[39] ASTM D638-14, Standard Test Method for Tensile Properties of Plastics, ASTM International, West Conshohocken, PA, USA, 2014, http://www.astm.org.

[40] ASTM D790-00, Standard Test Methods for Flexural Properties of Unreinforced and Reinforced Plastics and Electrical Insulating Materials, ASTM International, West Conshohocken, PA, USA, 2002, http://www.astm.org.

[41] ASTM D4812-19, Standard Test Method for Unnotched Cantilever Beam Impact Resistance of Plastics, ASTM International, West Conshohocken, PA, USA, 2019, http://www. astm.org.

[42] ASTM D6641/D6641M-16e1, Standard Test Method for Compressive Properties of Polymer Matrix Composite Materials Using a Combined Loading Compression (CLC) Test Fixture, ASTM International, West Conshohocken, PA, USA, 2016, http://www.astm.org.

[43] ASTM D570-98, Standard Test Method for Water Absorption of Plastics, ASTM International, West Conshohocken, PA, USA, 2018, http://www.astm.org.

[44] E. Agnantopoulou, V. Tserki, S. Marras, J. Philippou, and C. Panayiotou, "Development of biodegradable composites based on wood waste flour and thermoplastic starch," Journal of Applied Polymer Science, vol. 126, no. S1, pp. E273-E281, 2012.

[45] M. S. Huda, L. T. Drzal, M. Misra, and A. K. Mohanty, "Woodfiber-reinforced poly (lactic acid) composites: evaluation of the physicomechanical and morphological properties," Journal of Applied Polymer Science, vol. 102, no. 5, pp. 4856-4869, 2006.

[46] A. Ashori and A. Nourbakhsh, "Characteristics of wood-fiber plastic composites made of recycled materials," Waste Management, vol. 29, no. 4, pp. 1291-1295, 2009.
[47] S. M. L. Rosa, E. F. Santos, C. A. Ferreira, and S. M. B. Nachtigall, "Studies on the properties of rice-huskfilled-PP composites: effect of maleated PP," Materials Research, vol. 12, no. 3, pp. 333-338, 2009.

[48] Y. S. Munde and R. B. Ingle, "Theoretical modeling and experimental verification of mechanical properties of natural fiber reinforced thermoplastics," Procedia Technology, vol. 19, pp. 320-326, 2015.

[49] Y. S. Munde, R. B. Ingle, and I. Siva, "Effect of sisal fiber loading on mechanical, morphological and thermal properties of extruded polypropylene composites," Materials Research Express, vol. 6, no. 8, Article ID 085307, 2019.

[50] E. Trombetta, T. Flores-Sahagun, and K. G. Satyanarayana, "Evaluation of polypropylene/saw dust composites prepared with maleated polypropylene (mapp) produced by reactive extrusion," Matéria (Rio de Janeiro), vol. 15, no. 2, pp. 309-318, 2010.

[51] O. Shakuntala, G. Raghavendra, and A. Samir Kumar, "Effect of filler loading on mechanical and tribological properties of wood apple shell reinforced epoxy composite," Advances in Materials Science and Engineering, vol. 2014, p. 9, Article ID 538651, 2014.

[52] T. Gobikannan, H. Berihun, E. Aklilu et al., "Development and characterization of sisal fiber and wood dust-reinforced polymeric composites," Journal of Natural Fibers, vol. 17, pp. 1-10, 2020.

[53] M. R. Hossain, F. Hossain, and M. A. Islam, "Effects of wood properties on the behaviors of wood particle reinforced polymer matrix composites," Journal of Scientific Research, vol. 6, no. 3, pp. 431-443, 2014.

[54] S. Erdogan and U. Huner, "Physical and mechanical properties of PP composites based on different types of lignocellulosic fillers," Journal of Wuhan University of Technology (Materials Science) Editorial Department, vol. 33, no. 6, pp. 1298-1307, 2018.

[55] Q. Yuan, D. Wu, J. Gotama, and S. Bateman, "Wood fiber reinforced polyethylene and polypropylene composites with high modulus and impact strength," Journal of Thermoplastic Composite Materials, vol. 21, no. 3, pp. 195-208, 2008.

[56] S. C. Das, D. Paul, M. M. Fahad, M. K. Das, G. M. S. Rahman, and M. A. Khan, "Effect of fiber loading on the dynamic mechanical properties of jute fiber reinforced polypropylene composites," Advances in Chemical Engineering and Science, vol. 8, no. 4, pp. 215-224, 2018.

[57] G. Das and S. Biswas, "Effect of fiber parameters on physical, mechanical and water absorption behaviour of coir fiberepoxy composites," Journal of Reinforced Plastics and Composites, vol. 35, no. 8, pp. 644-653, 2016.

[58] C. Parida, S. K. Dash, and S. C. Das, "Effect of fiber treatment and fiber loading on mechanical properties of luffa-resorcinol composites," Indian Journal of Materials Science, vol. 2015, p. 6, Article ID 658064, 2015.

[59] N. Gebremedhin and G. K. Rotich, "Manufacturing of bathroom wall tile composites from recycled low-density polyethylene reinforced with pineapple leaf fiber," International Journal of Polymer Science, vol. 2020, p. 9, Article ID 2732571, 2020.

[60] I. Turku, A. Keskisaari, T. Kärki, A. Puurtinen, and P. Marttila, "Characterization of wood plastic composites manufactured from recycled plastic blends," Composite Structures, vol. 161, pp. 469-476, 2017.

[61] S. Kaewkuk, W. Sutapun, and K. Jarukumjorn, "Effects of interfacial modification and fiber content on physical properties of sisal fiber/polypropylene composites," Composites Part B: Engineering, vol. 45, no. 1, pp. 544-549, 2013. 